\title{
Shea Shells and Press-Cake as New Sources of Bioactive Phenolic Compounds: GC MS Profile and in vitro Antioxidant Activity
}

\author{
A. B. Kouakou, G. G. Doué, R.-M. Mégnanou, and A. E. S. Djoman
}

\section{ABSTRACT}

\begin{abstract}
Shea nuts shells and press cake are shea butter processing byproducts. Their content in phenolic bioactive compounds and their antioxidant capacity were studied. The total phenolic and flavonoid contents ranged between 16.962-21.395 mg GAE/100g DM and 0.243-1.83 mg QE/100g DM, for press-cake and shells, respectively. Antioxidant capacity values assessed by $\mathrm{EC}_{50}$ using DPPH, ABTS and FRAP methods were in the range of 0.398$0.235 \mathrm{mg} / \mathrm{mL}, 0.623-0.465 \mathrm{mg} / \mathrm{mL}$ and $0.137-0.154 \mathrm{mg} / \mathrm{mL}$ for shea presscake and shells, respectively. Shea shells recorded the highest total phenolic and flavonoid compounds positively correlated with DPPH and ABTS radical scavenging. Catechins, arbutin and gallic acid were the most abundant phenolic compound identified by GC-MS chromatography with 10.4; 2.1 and $0.8 \mathrm{~g} / 100 \mathrm{~g}$ in shea shells and $2.2 ; 2.6$ and $2.6 \mathrm{~g} / 100 \mathrm{~g}$ in presscake. Based on this phenolic composition shea nuts shells and press cake could be of great importance in cosmetic and pharmaceutical industries, and also contribute to preventing metabolic and cardiovascular diseases.
\end{abstract}

Keywords: antioxidant activity, GC-MS chromatography, phenolic compounds, shea press-cake, shea shells.

\section{INTRODUCTION}

Interest in natural antioxidants is increasing compared to synthetic antioxidants. Antioxidants have been defined as compounds that prevent, delay, or remove oxidation of any other chemical substance in their presence [1], [2]. These compounds are best known for their ability to stop chain reactions caused by electron transfer between substances by reducing with free radicals, thus neutralizing their oxidative damage on body [3]. In physiological conditions, oxygen produces the main oxidative species (ROS) which are particularly toxic for cellular integrity, especially on biomolecules such as lipids, proteins, DNA, and sugars. To protect against the toxic effects of oxygen, two defence systems have been reported to regulate the production of these ROS. These include antioxidants related to the endogenous system (enzymatic or non-enzymatic), but also exogenous molecules from diet [1], [3].

Over the past few decades, consumers have become aware of the health benefits of natural antioxidants from food and non-food sources and prefer stable products obtained through their use. These exogenous antioxidants, since they are natural, allow to avoid oxidative damage without causing other detrimental effects commonly observed with synthetic molecules [2]. Natural antioxidants have been proven to be safer because of their natural chemical forms that exist in
Published Online: September 24, 2021

ISSN: 2684-5199

DOI: $10.24018 /$ ejbio. 2021.2 .5 .252

\section{A. B. Kouakou}

Biosciences Faculty, Félix HouphouëtBoigny University, Côte d'Ivoire.

(e-mail: boriskouakou1993@gmail.com) G. G. Doué *

Biosciences Faculty, Félix HouphouëtBoigny University, Côte d'Ivoire. (e-mail: gladysdoue@yahoo.com) R. M. Mégnanou

Biosciences Faculty, Félix HouphouëtBoigny University, Côte d'Ivoire. (e-mail: megnanour@yahoo.fr)

A. E. S. Djoman

Biosciences Faculty, Félix HouphouëtBoigny University, Côte d'Ivoire. (e-mail: eliseeahouman2017@gmail.com)

*Corresponding Author

nature. Therefore, the need to research natural antioxidants is of greatest importance. Hence, many studies are performed on conventional or non-conventional raw materials, for that purpose. For instance, plants are screened in order to detect biologically active molecules that may have positive impact on human health. These bioactive molecules are either extracted and purified or exploited through their matrix (roots, leaves, seeds, etc.) into macerats or powders.

The main bioactive components of foods are glucosinolates, terpenoids and phenolic compounds [4]. Polyphenols are a class of secondary metabolites widely represented in the plant kingdom and therefore in our environment [5]. They are present in different parts of the plant (fruits, leaves, bark, roots etc.) and their structure includes one or more phenolic groups $(\mathrm{OH}$ group grafted onto an aromatic ring). These secondary metabolites, in addition to supporting the normal development of the organism, also help to maintain its integrity and healthy state when exposed to environmental stresses such as exposure to external temperatures and UV radiation [6]. They are commonly found in both edible and non-edible plants parts and exhibit a wide range of physiological properties such as anti-allergic, anti-inflammatory, anti-microbial, antioxidant, antithrombotic, and cardioprotective effects [7]. These properties are of great interest in the food, cosmetic and pharmaceutical industries, where they are sought after and used for many 
purposes, particularly as additives, colouring agents, and active ingredients, among many others [6], [8].

Shea (Vitellaria paradoxa, Gaertner), a plant that is widely distributed in the tropical belt from Senegal to Kenya is mainly present in the central and northern savannah regions in Côte d'Ivoire [8]. This plant is widely exploited for its butter due to the high demand from cosmetic, pharmaceutical and food industries. This butter is extracted from dry shea nuts that contain at least 50\% lipids [9] through different extraction methods. After fat extraction, byproducts referring to the nut's shells and press-cake remain. The large amount of nuts processed, about 100,000 tonnes per year, inevitably generates a huge amount of waste (shells and press-cakes) which to date have no economic value for local population. They are either left in heaps in the environment or often incinerated in open fires, thus contributing to environmental pollution [10].

However, byproducts from the agro-industrial sector are considered as an interesting and cheap source of bioactive compounds including high phenolic products [11]. Many studies on this topic have demonstrated the presence of phenolic compounds and their antioxidant activity in various byproducts [6], [11]. Moreover, author [10] reported the presence of phenolic compounds in shea nuts shell. Such information about the phenolic potential of shea shells and press-cake components would lead to a possible valorization of these byproducts. Hence, the present study aimed to highlight the antioxidant activity of shea nuts shells and press-cake, in order to exploit their use as cosmetical and therapeutical source of active phenolic molecules.

\section{MATERIAL AND METHODS}

\section{A. Material}

The material for this study were shells and press-cake obtained from the shea butter process. These shea byproducts were generated during the manufacture of shea butter. The seeds used for this purpose were provided by the Biotechnology Pedagogy and Research Unit (UPR) of Félix Houphouët-Boigny University (Côte d'Ivoire).

\section{B. Analytical Methods}

\section{1) Extraction of phenolic compounds}

The extraction process was performed by using maceration in hydromethanolic mixture as described by [12]. A suspension of $100 \mathrm{~g}$ of shea shells or press-cake powder in 1 L of $70 \%$ methanol (v/v), was homogenised under magnetic agitation for 48 hours, then filtered on hydrophilic cotton and Wattman paper $n^{\circ} 2$. The solvant was evaporated at $40{ }^{\circ} \mathrm{C}$ using a rotating evaporator until a dried powder was obtained. The resulting powders of shea shells and press-cake were stored in sterile vials at $4{ }^{\circ} \mathrm{C}$ for further analysis.

\section{2) Dosage of phenolic compounds in shea shells and press-cakes}

\section{1) Total phenolic content (TPC)}

TPC was determined by spectrophotometry method using Folin ciocalteu reagent, according to [13] with some modifications. Thus, dry extract was dissolving in the same solvent ( $70 \%$ methanol) previously used for the extraction at
$1 \mathrm{mg} / \mathrm{mL}$ and then diluted to an appropriate concentration for analysis.

One (1) $\mathrm{mL}$ of methanolic extract was introduced into a test tube and $1 \mathrm{~mL}$ of Folin-Ciocalteu reagent was added. The tube was allowed to stand for $3 \mathrm{~min}$ and then $1 \mathrm{~mL}$ of $20 \%$ (w/v) sodium carbonate solution was added. The contents of the tube were made up to $10 \mathrm{~mL}$ with distilled water. The tube was placed in the dark for $30 \mathrm{~min}$ and Absorbance was read with a UV-vis spectrophotometer (UV-1800, Pioway, China) at $725 \mathrm{~nm}$ against a blank.

A standard curve was established from gallic acid stock solution $(1 \mathrm{mg} / \mathrm{mL})$, to determine the amount of polyphenol in the sample expressed as gallic acid equivalents (g GAE per $100 \mathrm{~g}$ of dry weight).

\section{2) Total flavonoids content (TFC)}

TFC of byproducts extract (shea shells or press-cake) was evaluated following the methodology described previously [14]. One (1) g of methanolic extract (shea shells or press cake) previously prepared was mixed with $10 \mathrm{~mL}$ of $70 \%$ $(\mathrm{v} / \mathrm{v})$ methanol. After centrifuged at $115 \mathrm{~g}$ for $10 \mathrm{~min}$ using a LABOFUGE centrifuge (ThermoScientific, France) the pellet was recovered in $10 \mathrm{~mL}$ of $70 \%(\mathrm{v} / \mathrm{v})$ methanol and centrifuged again. The resulting supernatants were collected in $50 \mathrm{~mL}$ flask and adjusted to the mark with distilled water. A volume of $0.5 \mathrm{~mL}$ of this methanolic extract was collected and mixed with $0.5 \mathrm{~mL}$ of distilled water, $0.5 \mathrm{~mL}$ of aluminium chloride, $0.5 \mathrm{~mL}$ of sodium acetate and $2 \mathrm{~mL}$ of distilled. The tube was allowed to stand at room temperature in the dark for $30 \mathrm{~min}$. The absorbance was measured with a UV-vis spectrophotometer (UV-1800, Pioway, China) at $415 \mathrm{~nm}$ against a blank. A calibration curve was performed with $0.1 \mathrm{mg} / \mathrm{mL}$ quercetin stock solution and the results were expressed as $\mathrm{g}$ of quercetin equivalents per $100 \mathrm{~g}$ of dry weight.

\section{3) Evaluation of the antioxidant activity \\ 3.1) DPPH Assay}

A DPPH radical scavenging assay was performed as described previously [15], using 0.1 mM DPPH solution. The absorbance was recorded at $517 \mathrm{~nm}$ with UV-vis spectrophotometer (UV-1800, Pioway, China) then diluted to an appropriate concentration for analysis. For different concentration $(0,0.01,0.025,0.05,0.1,0.2,0.3,0.4,0.5,0.75$ and $1 \mathrm{mg} / \mathrm{mL}$ ) of samples. The scavenging activity was calculated by using equation (1):

$\%$ of DPPH Inhibition $=\frac{[A b s o-(A b s-A b 1)]}{A b s o} \times 100$

where Abso is the absorbance of the control reaction (test solution with ethanol and DPPH), Abs the absorbance of the sample and $\mathrm{Ab} 1$ the blank absorbance.

Dose response curves were constructed for $\mathrm{EC}_{50}$ estimation. $\mathrm{EC}_{50}$ is the concentration of sample required to scavenge $50 \%$ of the free radical. These concentrations were expressed in $\mathrm{mg} / \mathrm{mL}$ and BHT was used as standard.

\section{2) FRAP (Ferric reducing antioxidant power) assay}

FRAP assay was performed as described previously [16], using chlorure ferric reagent. The absorbance of samples at different concentration $(0,0.01,0.025,0.05,0.1,0.2,0.3,0.4$, $0.5,0.75$ and $1 \mathrm{mg} / \mathrm{mL}$ ) was measured at $700 \mathrm{~nm}$ using UVvis spectrophotometer (UV-1800, Pioway, China). The final 
absorbance of each sample was compared with those obtained from BHT standard curve. The results were expressed as the concentration $(\mathrm{mg} / \mathrm{mL})$ of sample required to reduce $50 \%$ of the iron $\left(\mathrm{EC}_{50}\right)$.

3.3) ABTS (2,2' azion-bis 3- ethylbenzothizoline-6-sulfonic acid) assay

This assay is one of the most used method for determining of antioxidant activity of plant extracts. It consists on the discoloration kinetics of the ABTS ion as described by previously [17]. The absorbance was recorded at $734 \mathrm{~nm}$ on a UV-vis spectrophotometer (UV-1800, Pioway, China) for different concentration $(0,0.01,0.025,0.05,0.1,0.2,0.3,0.4$, $0.5,0.75$ and $1 \mathrm{mg} / \mathrm{mL}$ ) of samples. The percentage of inhibition or antioxidant activity (AA) was calculated by using the equation (2):

$$
\mathrm{AA}(\%)=\frac{\text { Ainitial }- \text { Aassay }}{\text { Ainitial }} \times 100
$$

Dose response curves were plotted for $\mathrm{EC}_{50}$ determination. $\mathrm{EC}_{50}$ is defined as the concentration of sample required to scavenge $50 \%$ of the free radical. These concentrations were expressed in $\mathrm{mg} / \mathrm{mL}$ and BHT was used as standard.

\section{4) Phenolic compounds identification and measurement by $G C-M S$}

Samples were extracted using a diethylamine/water/acetonitrile (10:40:50) mixture and the derivatized analytes (BSTFA-TMCS) were analyzed by gas chromatography/mass spectrometry (GC-MS). Derivatisation in GC aims at transforming compounds into derivatives with a close chemical structure but with reduced polarity so as to make them volatile for analyzing. For this, sample powder $(50 \mu \mathrm{g})$ was mixed with $250 \mu \mathrm{L}$ of N,O-Bis (trimethylsilyl) trifluoroacetamide, Trimethylchlorosilane (BSTFA + TMCS, 99:1) and $250 \mu \mathrm{L}$ of pyridine. The resulting mixture was vortexed for $2 \mathrm{~min}$ and then heated to $70{ }^{\circ} \mathrm{C}$ in an oven for 30 min. One (1) $\mu \mathrm{L}$ of the resulting solution was injected into the GC-MS for analysis.

The GC-MS analysis was carried out on a PerkinElmerMS Clarus $500 \mathrm{C}$ with a $30 \mathrm{~cm}$ long column with an internal diameter of $0.25 \mathrm{~mm}$ and a stationary phase film thickness of $0.25 \mu \mathrm{m}$. Helium was used as a carrier gas with a fixed flow rate of $0.75 \mathrm{~mL} / \mathrm{min}$. The oven temperature programme was $50{ }^{\circ} \mathrm{C}$ for $2 \mathrm{~min}$, then a gradient of $5^{\circ} \mathrm{C} / \mathrm{min}$ was applied up to $350{ }^{\circ} \mathrm{C}$. The latter temperature was maintained for $14 \mathrm{~min}$ for a total analysis time of $60 \mathrm{~min}$. The temperature of the injector was set at $350{ }^{\circ} \mathrm{C}$. The injection was carried out in split mode with a ratio of 1:50. The mass spectrometer was set up in electron impact mode with an ionisation source temperature of $200{ }^{\circ} \mathrm{C}$, an electron energy of $70 \mathrm{eV}$, a scanning speed of 200 scans/min and a scanning range between 50 and $800 \mathrm{~m} / \mathrm{z}$. Peaks were identified using both pure standards and spectrum comparison.

\section{Statistical Analysis}

All measurements were recorded in triplicate (except for GC-MS identification) and results were expressed as mean \pm standard deviation. In addition, the results were subjected to a one-way analysis of variance (ANOVA) followed by the LSD Post Hoc test for correlation tests. Difference between the means was evaluated by Duncan test at significance level of $p<0.05$ using the 2006 version of the Statistica 7.1 software.

\section{RESULTS AND DISCUSSION}

\section{A. The Percentage of Phenolic Compounds Yield}

The extraction yield of phenolics compounds was calculated as the ratio between the mass of extract on the initial sample mass (Table I).

TABLE I: PERCENTAGE YIELD OF PHENOLIC COMPOUNDS OF METHANOLIC EXTRACT FROM SHEA BYPRODUCTS

\begin{tabular}{cccc}
\hline & TPC & TFC & Yield \\
& g GAE/100 g DM & g QE/100g DM & $(\%)$ \\
\hline SS extract & $21.395 \pm 0.15^{\mathrm{a}}$ & $1.832 \pm 0.11^{\mathrm{a}}$ & $7.2 \pm 0.1^{\mathrm{b}}$ \\
SP-C extract & $16.962 \pm 0.22^{\mathrm{b}}$ & $\underline{0.243 \pm 0.01^{\mathrm{b}}}$ & $21.3 \pm 0.3^{\mathrm{a}}$ \\
\hline
\end{tabular}

a, b, Means followed by different letters in the same column are significantly different $(\mathrm{p} \leq 0.05)$. Values in bold are the highest. GAE: gallic acid equivalent; QE: quercetin equivalent; DM: dry matter; SS: shea shell; SP-C: shea press-cake.

The data show that methanol extract of shea press-cake $(21.3 \pm 0.3 \%)$ has higher phenolic compounds content than shea shells $(7.2 \pm 0.3 \%)$. In this study, methanol was used as extraction medium because of its high polarity with phenolic compounds. Thus, the difference in extraction level observed with this solvent highlights the difference in polarity between the phenolic compounds of the various shea byproducts studied [18].

\section{B. Phenolic Compounds Content of Shea Shells and Press- cake}

Among the main groups of phenolic compounds are total phenolics, flavonoids, tannins (hydrolysable and condensed), stilbenes and lignans [19]. So far as plant phenolics constitute one of the major groups of compounds acting as primary antioxidants or free radical terminators, it was reasonable to determine their total amount in the shea byproduct extracts [20]. Therefore, the content of total phenolics was determined in the studied shea byproducts extracts (shells and presscake). The results underlined a significant difference $(p<0.05)$ between shells and press-cake (Table I). Indeed, shea shells recorded the higher total phenolics content $(21.395 \pm 0.24 \mathrm{~g} \mathrm{Eq} \mathrm{AG} / 100 \mathrm{~g} \mathrm{DM})$ than shea press-cakes with $16.962 \pm 0.22 \mathrm{~g} \mathrm{Eq} \mathrm{AG/100g} \mathrm{DM.} \mathrm{As} \mathrm{many} \mathrm{factors} \mathrm{affect}$ polyphenol biosynthesis (geographical region, climate, and postharvest handling) [21], [22], it is not surprising to find differences between phenolic contents from various parts of the same plant. In addition, the high content of phenolic compounds in the methanolic extract of shea shells compared to that of press-cake underlines their potential as food fortificant or pharmaceutical and/or cosmetic ingredient.

Similarly, to TPC, methanolic extracts of shea shell showed the highest total flavonoid content $(1.832 \pm 0.00 \mathrm{~g}$ Quercetin Eq/100g DM) compared to methanolic extracts of press-cake with $0.243 \pm 0.01 \mathrm{~g}$ Quercetin Eq/100g DM (Table I). Methanol extraction also yielded higher total flavonoid concentrations compared to different date varieties (Ghar, Deglet and Mech-Degla with 0.143, 0.136 and $1.05 \mathrm{mg}$ $\mathrm{EQ} / 100 \mathrm{~g}$ of DM, respectively) as observed by authors [23]. Therefore, these high contents in total flavonoids allow to consider these shea byproducts as excellent natural sources of bioactive compounds and thus consider their use in the 
various food and non-food industries due to their possible impact on nutrition and consumers health [24].

It should be noted that the same shea by-product (shea press-cake) displayed the highest content for both total phenols and flavonoids. This trend was confirmed by the study of the correlation between these two phenolic variables (Table II) as the results indicated that the correlation factor was high and significant $(\mathrm{r}=0.997, \mathrm{p}<0.01)$.

TABLE II: PEARSON COEFFICIENTS OF CORRELATION (R) BETWEEN BIOACTIVE COMPOUNDS (TOTAL PHENOLICS AND TOTAL FLAVONOIDS) AND ANTIOXIDANT CAPACITIES (MEASURED BY DPPH, ABTS AND FRAP

\begin{tabular}{cccccc}
\multicolumn{5}{c}{ ASSAYS $)$} \\
& $\begin{array}{c}\text { Total } \\
\text { phenolics }\end{array}$ & $\begin{array}{c}\text { Total } \\
\text { flavonoid }\end{array}$ & DPPH & ABTS & FRAP \\
\hline Total & 0.997 & & & & \\
flavonoid & 0.999 & 0.998 & & \\
DPPH & 0.989 & 0.998 & 0.995 & & \\
ABTS & -0.962 & -0.973 & -0.968 & -0.980 & \\
FRAP & & & & \\
\hline
\end{tabular}

Correlation is significant at $\mathrm{p}<0.01$.

These results allowed to emphasize that flavonoids are the main components among the polyphenolic compounds of shea press-cake. The same behavior was observed by a team of Tai researchers [25] on ethanolic extracts from various parts of native plants $(r=0.9)$ thus underlining the high presence of these compounds in the plant kingdom.

\section{Antioxidant Capacity of Shea Shells and Press-cake}

Since the different types of antioxidant activity assays are based on specific mechanisms, it is important to measure antioxidant activity by more than one type of method to account for the different possible mechanisms involved in antioxidant activity [21] and then evaluate the total antioxidant capacity. Therefore, three kinds (DPPH, ABTS and FRAP) of antioxidant assays were carried out (Fig. 1).
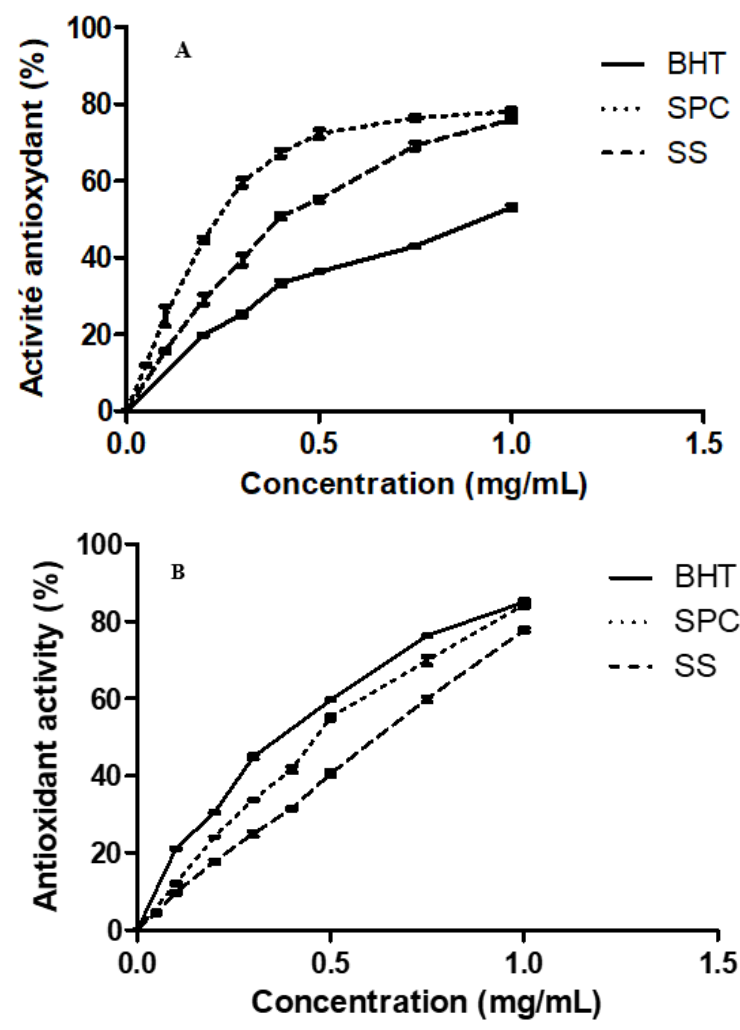

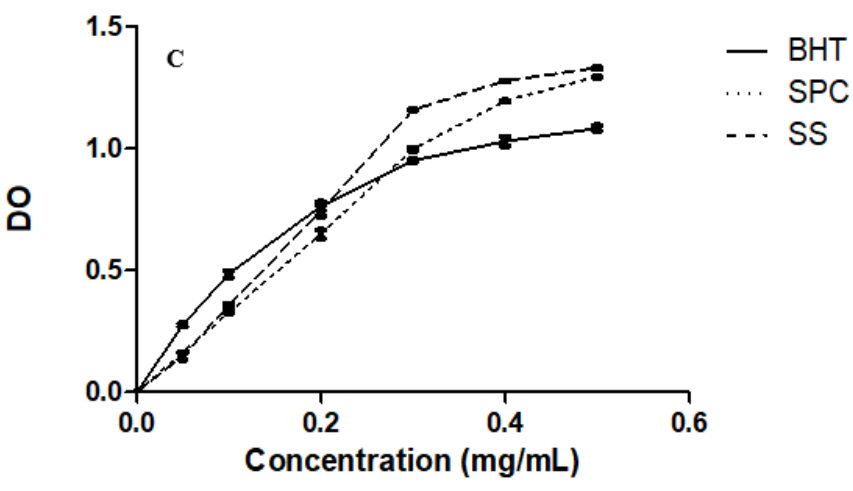

Fig. 1. Antioxidant power DPPH (A), ABTS (B), FRAP (C) of shea byproducts extracts compared to antioxidant power of standard (BHT) at different concentration.

Spc: shea press-cake; SS: shea shells.

All these assays (DPPH, ABTS and FRAP) demonstrated a higher antioxidant power of shea shells/ press-cakes compared to the well-known BHT activity (Fig. 1). This antioxidant activity is higher than that of DPPH at all concentrations of the two extracts while for ABTS it remains lower but closer to the reference BHT radical. On the other hand, concerning FRAP reducing power, these extracts had higher antioxidant activity below $0.2 \mathrm{mg} / \mathrm{mL}$.

The $\mathrm{EC}_{50}$ value, corresponding to the concentration of antioxidant required to reduce $50 \%$ of the radicals (DPPH or ABTS+) by scavenging or $50 \%$ of the metals (FRAP) within a fixed time period, provides a measure of this activity. A smaller $\mathrm{EC}_{50}$ value corresponds to a higher antioxidant activity of the extract. Results expressed as the $\mathrm{EC}_{50}$ of the different extracts provided an overview of the antioxidant capacity (Table III).

The results showed that the methanolic extract of shea byproducts had proved to be more effective scavenging DPPH radical with $\mathrm{EC}_{50}$ value of $0.235 \pm 0.001$ and $0.398 \pm 0.006 \mathrm{mg} / \mathrm{mL}$ for press-cake and shea shells, respectively than $\mathrm{BHT}\left(\mathrm{EC}_{50}=0.924 \mathrm{mg} / \mathrm{mL}\right)$.

TABLE III: ANTIOXIDANT CAPACITY OF THE EXTRACTS IN COMPARISON WITH THE BHT REFERENCE

\begin{tabular}{cccc}
\hline & \multicolumn{3}{c}{$\mathrm{EC}_{50}(\mathrm{mg} / \mathrm{mL})$} \\
\hline & DPPH & FRAP & ABTS \\
\hline SS extract & $\underline{0.235 \pm 0.001^{\mathrm{c}}}$ & $0.154 \pm 0.006^{\mathrm{a}}$ & $0.465 \pm 0.014^{\mathrm{b}}$ \\
SP-C extract & $0.398 \pm 0.006^{\mathrm{b}}$ & $0.137 \pm 0.002^{\mathrm{b}}$ & $0.623 \pm 0.025^{\mathrm{a}}$ \\
BHT & $0.924 \pm 0.014^{\mathrm{a}}$ & $\underline{0.105 \pm 0.005^{\mathrm{c}}}$ & $\underline{0.401 \pm 0.041^{\mathrm{c}}}$ \\
\hline a, b, c $^{\mathrm{c}}$ Means followed by different letters in the same column are significantly \\
different ( $\mathrm{p} \leq$ 0.05). Values in bold are the highest and those underlined are \\
the lowest; SS: Shea shell; SP-C: shea press-cake.
\end{tabular}

This report indicates the good potential of these shea byproducts extracts as source of bioactive compounds of interest. This finding opens up new possibilities for shea added value as these phenolic compounds could be used in foods and non-foods industries to replace synthetic phenolic compounds like BHT (3,5-ditertiobutyl-4-hydroxytoluene) [26].

As previously reported, methanolic shell extracts with both higher total phenolic and flavonoid contents also exhibited the highest DPPH scavenging activity $(p<0.05)$ with the lowest $\mathrm{EC}_{50}(0.235 \pm 0.001 \mathrm{mg} / \mathrm{mL})$ indicating a relatively high antiradical activity. This suggests that phenolic compounds of shea byproduct extracts, and particularly those of flavonoid nature, could act as terminating agents by 
trapping radicals, transforming them into more stable compounds and thus blocking the propagation phase. Such an effect would result from a structure of $\mathrm{H}^{*}$ donors often aromatic, typical of phenol derivatives (tocopherols, polyphenols, flavonoids) [26].

Another screening method for antioxidant activity, ABTS (specific to lipophilic and hydrophilic antioxidants) was studied. Contrary to the results obtained with DPPH, it can be seen that BHT has the highest inhibition capacity of the ABTS $^{*+}$ cation radical, with the lowest $\mathrm{EC}_{50}$ $(0.401 \pm 0.041 \mathrm{mg} / \mathrm{mL}), \quad$ compared to shells $(0.623 \pm 0.025 \mathrm{mg} / \mathrm{mL})$ and the press-cakes $(0.465 \pm 0.0014$ $\mathrm{mg} / \mathrm{mL})$. In addition, the studied shea byproduct exhibited significantly different antioxidant activity $(\mathrm{p}<0.05)$ on $\mathrm{ABTS}^{++}$. According to previous research [27] this ability could be explained by the presence of high molecular weight phenolic compounds that are more efficient in the scavenging of free radicals.

Fe (III) reduction (Feeric Reducing Power) is often used as an indicator of electron-donating activity, which is an important mechanism of phenolic antioxidant reaction [28]. The presence of reductants (antioxidants) in the shea byproduct extracts causes the reduction of the $\mathrm{Fe}^{3+} /$ ferricyanide complex to the ferrous form. The concentration of $\mathrm{Fe}^{2+}$ monitored by measuring the formation of Perl's Prussian blue at $700 \mathrm{~nm}$ are presented in Table III. In this assay, the $\mathrm{EC}_{50}$ values of $0.154 \mathrm{mg} / \mathrm{mL}$ (press-cake) and $0.137 \mathrm{mg} / \mathrm{mL}$ (shells) also showed particularly lower ferric reducing ability than the reference BHT $\left(\mathrm{EC}_{50}=0.105\right)$ which exhibited the highest reducing activity.

\section{Correlation between Total Phenolic/Flavonoid Content and Antioxidant Activity}

The antioxidant activity of polyphenols is mainly due to their ability to act as hydrogen donors, reducing agents and/or radical scavengers [29].

Relationship between the studied parameters was assessed through Pearson correlation. This study revealed positive and significantly high correlation coefficient values between total phenolics and both DPPH (0.999) and ABTS (0.989) radical scavenging methods in contrast to the FRAP reducing method $(-0.962)$, with a high negative correlation value for the shells and the press cake (Table II).

The same pattern was observed between total flavonoids and the three antioxidant methods evaluated DPPH (0.998), ABTS (0.998) and FRAP (-0.973). However, only the DPPH and ABTS methods showed an excellent positive correlation with flavonoids highlighting the concordance between these phenolic compounds and the shea byproducts antioxidant activity. Thus, indicates on the one hand that the flavonoid compounds are the major contributors to the antioxidant properties in these plants. Moreover, the strong and positive correlation observed with DPPH and ABTS methods would suggest the presence of various phenolic compounds with different trends of antioxidant activity [29]. Indeed, the authors [30] underline that the resulting antioxidant activity in a plant would be strongly influenced by the synergistic effects caused by the various associations between its biomolecules.

\section{E. Identification and Evaluation of the Different Shea Byproducts Phenolic Compounds}

In plant structures, phenolic compounds exist in both free forms dissolved in the medium and bound forms (glycosylates) with a predominance of the bound forms in the raw plant matrix, in contrast to the free fraction (aglycone) that predominates in processed foods [31].

Individual phenolic compounds of the studied shea byproducts are depicted in Fig. 2. Fig. 2A and 2B showed representative chromatograms from shea shells and presscake, respectively.
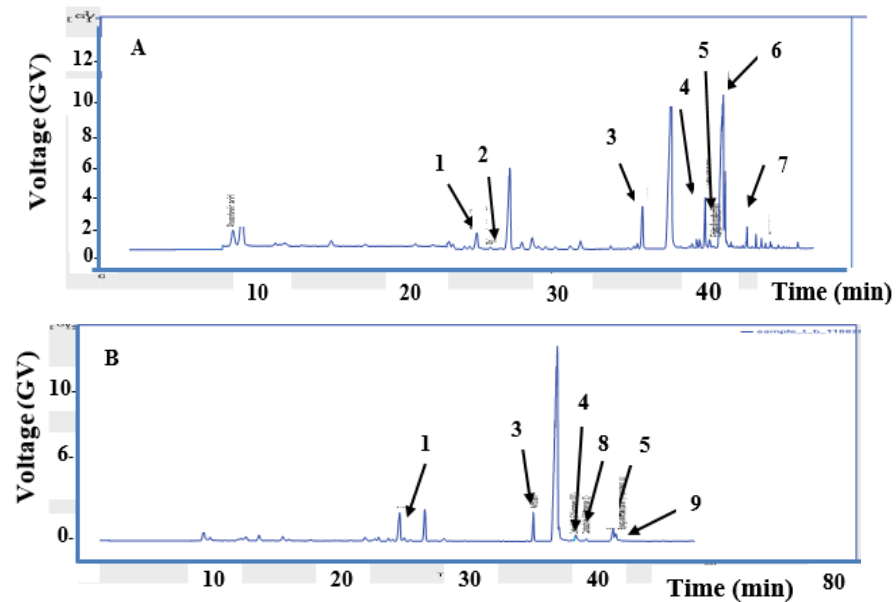

Fig. 2. Gas chromatography chromatogram profile of shea byproducts phenolic compounds: shells (2A) and press-cake (2B).

The resulting peaks were identified by comparing their retention times and spectra, with those obtain pure GC-grade standards. 1: gallic acid; 2: phloroglucinic acid; 3: arbutin; 4: (-)-catechin; 5: (-)-epigallocatechin; 6: (+)-catechin; 7: quercetin; 8: (-)-epicatechin; 9: (-)-epigallocatechin gallate.

The different samples chromatogram's peak areas were superposed with those of pure phenolic standards in order to identify the different shea byproducts compounds based on their retention time. These profiles indicated that the samples consist mainly of gallic acid, arbutin, and catechin with its isomers (Fig. 2A and 2B) for both shea byproducts (presscake and shell methanolic extract) and phloroglucinic acid and quercetin (Fig. 2A), at low levels, only in shea shell byproduct. It should be noticed that catechin isomers were detected as (-)-catechin C, (+)-catechin C, (-)epigallocatechin EGC, (-)-epicatechin EC and (-)epigallocatechin gallate EGCg. Phenolic compounds contents are shown on Table IV for shea press-cake and shells.

The analysis of results (Table IV) showed that the phenolic compounds are present in different proportions.

TABLE IV: IDENTIFICATION AND QUANTIFICATION OF INDIVIDUAL Phenolic COMPounds (G/100 G DM) IN SHEA SHELls AND PRESS CAKE SAMPLES

\begin{tabular}{cccccccccc}
\hline & \multirow{2}{*}{ Gallic acid } & \multirow{2}{*}{ Arbutin } & \multicolumn{9}{c}{ Catechins } & \multicolumn{4}{c}{$\begin{array}{c}\text { Phloroglucinic } \\
\text { acid }\end{array}$} & Quercetin \\
\cline { 3 - 7 } & & $\mathrm{A}_{1}$ & $\mathrm{~A}_{2}$ & $\mathrm{~A}_{3}$ & $\mathrm{~A}_{4}$ & $\mathrm{~A}_{5}$ & & 0.5 \\
\hline SS & 0.8 & 2.1 & 2.7 & 7.3 & 0.4 & - & - & 0.2 & - \\
SP-C & 2.6 & 2.6 & 0.1 & - & 1.2 & 0.2 & 0.7 & - & - \\
\hline
\end{tabular}

Catechins isomers: (A1): (-)-catechin C; (A2): (+)-catechin C; (A3): (-)-epigallocatechin EGC; (A4): (-)-epicatechin EC; (A5): (-)-epigallocatechin gallate EGCG; DM: dry matter. 
Catechins are the major constituents (10.4 g/100 g DM), followed by arbutin (2.1 g/100 $\mathrm{g} \mathrm{DM})$ and gallic acid $(0.8 \mathrm{~g} / 100 \mathrm{~g} \mathrm{DM})$ in shells extract; whereas in press-cake extract, these three constituents were present at $2.2 \mathrm{~g} / 100 \mathrm{~g}$ DM (catechins), $2.6 \mathrm{~g} / 100 \mathrm{~g} \mathrm{DM}$ (arbutin) and $2.6 \mathrm{~g} / 100 \mathrm{~g}$ DM (gallic acid). On the other hand, the phenolic compounds of shea shells recorded low contents with $0.5 \mathrm{~g} / 100 \mathrm{~g}$ DM (quercetin) and $0.2 \mathrm{~g} / 100 \mathrm{~g} \mathrm{DM}$ (ploroglucinic acid).

Among the main common molecules identified, catechins have been extensively studied for their beneficial health effects [31], [32]. This fraction of polyphenolic compounds from flavonoid family and particularly epigallocatechin gallate (EGCg), is a potent antioxidant with anti-obesity effects. It is particularly sought after in the cosmetic industry for the formulation of slimming treatments and in the pharmaceutical industry where it is used in the manufacture of dietary supplements as an appetite suppressant or fat burner, since it stimulates lipolysis [32]. Thus, this identification of natural molecules in shea byproducts really highlights their interest in cosmetic and pharmaceutical industries. Another main phenolic compound identified in the study was arbutin. This natural hydroquinone beta-Dglucophyranoside with antioxidant property [33], is an inhibitor of melanin formation and a skin lightening agent used in products used to treat skin cancer [34], [35]. This first identification of arbutin in shea byproducts, to the best of our knowledge, expanding their application in cosmetics and pharmacy. Tout comme les précédentes molecules, gallic acid (3, 4, 5-trihydroxybenzoic acid) and its derivatives are widely present in the plant kingdom and represent a large family of secondary polyphenolic plant metabolites. They are known to display antioxidant activity by the ability to counteract the damaging effects of free radicals in tissues and thus are believed to protect against cancer, arteriosclerosis, heart disease, and several other diseases [36]. Tout comme les précédentes molecules, gallic acid or 3, 4, 5trihydroxybenzoic acid and ester derivatives are widely distributed in higher plants. These phenolic compounds characterized by the presence of two functions (carboxylic and phenolic) in their structure are also known to display antioxidant activity. Thus, their significant presence in shea butter byproducts makes them excellent sources of bioactive compounds.

\section{CONCLUSION}

GC-MS analysis carried out on shea shells and press-cake highlighted their interesting bioactive compounds. The antioxidant ability of these two shea byproducts was also prooved. Furthermore, shea shells, exhibited the highest total phenolic and total flavonoid contents positively correlated with DPPH and ABTS scavenging radicals, indicating their potential antioxidant capacity. In addition, analysis of the phenolic compounds profile of these two shea byproducts revealed several phenolic compounds among them catechins, arbutin and gallic acid were the main common molecules. These results suggest that two shea byproducts (shells and press-cake) could serve as valuable sources of natural antioxidant. They could be of great importance in cosmetic and pharmaceutical industries, and also contribute to prevent metabolic and cardiovascular diseases.

\section{ACKNOWLEDGMENT}

This work was supported by a Ph.D. grant to the first author.

\section{REFERENCES}

[1] B. Halliwell, and J. M. Gutteridge, "The definition and measurement of antioxidants in biological systems," Free Radic Biol Med, vol. 18(1), pp. 125-126, 1995.

[2] B. Halliwell,"Dietary polyphenols: good, bad, or indifferent for your health?," Cardiovasc Res, vol. 73(2), pp. 341-347, 2007.

[3] T. M. Heikal, A. T. H. Mossa, G. I. K. Marei, and M. A. Abdel Rasoul, "Cyromazine and Chlorpyrifos Induced Renal Toxicity in Rats: The Ameliorating Effects of Green Tea Extract," J Environ Anal Toxicol, vol. 2(1), pp. 146-152. 2012.

[4] J. C. Espin, R. Gonzàlez-Barrio, B. Cerdà, C. Lòpez-Bote, A. I. Rey, and F. A. Tomàs-Barberàn, "Iberian pig as a model to clarify obscure points in the bioavailability and metabolism of ellagitannins in humans," J Agric Food Chem, vol. 55, pp.10476-85, 2007.

[5] F. Shahidi, and J. D. Yeo, "Insoluble-Bound Phenolics in Food," Molecules, vol. 21, pp. 1216 doi: 10.3390/molecules21091216, 2016.

[6] F. Shahidi, and H. Peng, "Bioaccessibility and bioavailability of phenolic compounds," J Food Bioact, vol. 4, pp. 11-6, 2018.

[7] B. D. Okai, and M. K. L. Bonsi, "Sheanut cake as a substitute for maize in the diets of growing gilts," Journal of the University of Science and Technology, vol. 9, pp. 45-50, 1989.

[8] J. B. Hall, D. P. Aebischer, H. F. Tomlinson, E. Osei-Amaning, J. R Hindle, "Vitellaria paradoxa: a monograph. School of Agricultural and Forest," Wales: Bangor University of Sciences Publication, $105 \mathrm{pp}$. 1996.

[9] R. R. B. Leakey, "Potential for novel food products from agroforestry trees: a review," Food Chem, vol. 66, pp. 1-14. 1999.

[10] A. E. S. Djoman, "Etude comparée du profil phytochimique et de quelques proprietes cosmetiques de produits du karite (coque, amande, beurre) et de cinq huiles d'interet commercial (nigelle, onagre, fenugrec, avocat, amande douce)," Mémoire de master en Biotechnologie Agroalimentaire, UFR Biosciences, Université Félix Houphouët-Boigny Abidjan, Côte d'Ivoire, 49 p. 2018.

[11] H. Peng, Z. Deng, X. Chen, Y. Sun, B. Zhang, and H. Li, "Major chemical constituents and antioxidant activities of different extractsn from the peduncles of Hovenia acerba Lindl," Int J Food Prop, vol. 21 n 1, pp. 2135-2155, 2018.

[12] F. Guede-Guina, A. M. Kra, M. Vangah-Manda, G. Bonga, and C. De Souza, "Inhibition par MISCA6F2 de la croissance de Aspergillus fumigatus; Candida albicans et Cryptococcus neoformans, 3 germes fongiques opportunistes au cours du SID," Afr J Biomed Res, vol. 2, pp. 11-16, 1997.

[13] V. L. Singleton, E. Orthofer, and R. M. Lamuela-Raventos, "Analysis of total phenols and other oxidation substrates and antioxidants by means of Folin-Ciocalteu reagent, " Methods Enzymol, vol. 299, pp. 152-178, 1999.

[14] A. Meda, C. E. Lamien, L. Romito, J. Millogro, O. G. "Nacoulma Detemination of total phenolic, flavonoid and proline contents in Burkina Fasso honeys as well as theis scavebging activity," Food Chem, vol. 91, pp. 571-577, 2005.

[15] N. Benhammou, B. Atik, and T. K. Panovska, "Antiradical capacity of the phenolic compounds of Pistacia lentiscus L. and Pistacia atlantica Desf," Adv Food Sci, vol. 29 n³, pp. 155-161, 2007.

[16] M. Oyaizu, "Antioxidative activities of browning reaction prepared from glucosamine,” Jpn J Nutr Diet, vol. 44, pp. 307-315, 1986.

[17] R. Re, N. Pellegrini, A. Proteggente, A. Pannala, M. Yang, C. RiceEvans, "Antioxidant activity applying an improved ABTS radical cation decolorization assay," Free Radic Biol Med, vol. 26, pp. 1231$1237,1999$.

[18] R. Jolkumen-Tiito, "Phenolics constituents in the leaves of northen willows: methods for the analysis of certain phenolics," J Agric Food Chem, vol. 33, pp. 213-217, 1985.

[19] M. K. Khan, Z.-E. Huma, and O. Dangles, "A comprehensive review on flavanones, the major citrus polyphenols," J Food Compos Anal, vol 33, pp. 85-104, 2014.

[20] P. K. Agrawal, editor. Carbon-13 NMR of flavonoids. New York: Elsevier, 580 p. 1989.

[21] G. F. Deng, X. Lin, X. X. R. Xu, L. L. Gao, J. F. Xie, and H. B. Li, "Antioxidant capacities and total phenolic contents of 56 vegetables," J Funct Foods, vol. 5 n 1, pp. 260-266, 2013.

[22] R. Goyenech, S. Roura, A. Ponce, A. Vega-Galvez, L. Quispe-Fuentes, E. Uribe, and K. Di Scala, "Chemical characterization and antioxidant 
capacity of red radish (Raphanus sativus) leaves and roots," J Funct Foods, vol. 16, pp. 256-264, 2015.

[23] S. D. Amiour, O. Alloui-Lombarkia, F. Bouhdjila, A. Ayachi, and L. Hambaba, "Etude de l'importance des composés phénoliques des extraits de 3 variétés de datte dans son activité antibactérienne," Phytotherapie, vol. 10, pp. 135-142, 2014.

[24] G. Miliauskas, P. R. Venskutonis, T. A. Van Beek, "Screening of radical scavenging activity of some medical and aromatic plant extract," Food Chem, vol. 85 n 2, pp. 231-237, 2004.

[25] P. Maisuthisakul, M. Suttajit, and R. Pongsawatmanit, “ Assessment of phenoliccontent and free radical-scavenging capacity of someThai indigenous plants," Food Chem, vol. 100(4), pp. 1409-1418, 2007.

[26] F. Marc, A. Davin, L. Deglene-Benbrahim, C. Ferrand, M. Baccaunaud, and P. Fritsch, "Méthodes d'évaluation du potentiel antioxydant dans les aliments," Med/Sci, vol. 20(4), pp. 458-463, 2004

[27] R. Banerjee, A. K. Verma, A. K. Das, V. Rajkumar, A. A. Shewalkar, H. P. Narkhede, "Antioxidant effects of broccoli powder extract in goat meat nuggets," Meat Sci, vol. 91(2), pp. 179-184, 2012.

[28] I. Hinneburg, H. J. D. Dorman, R. Hiltunen, "Antioxidant activities of extracts from selected culinary herbs and spices." Food Chem, vol. 97, pp. 122-129, 2006

[29] T.T. Mai, N. Fumie, and N.V. Chuyen, "Aantioxidant activities and hypolipidemic effects of an aquous extract from flower buds of Cleistocalyx operculatus (Roxb) merr and perr," J. Food Biochem, vol. 33, pp. 790-807, 2009.

[30] J. Yeo, F. Shahidi, "Critical evaluation of changes in the ratio of insoluble bound to soluble phenolics on antioxidant activity of lentils during germination," J Agric Food Chem, vol. 63(2), pp. 379-81, 2015.

[31] A. Podsedeck, "Natural antioxidants and antioxidant capacity of Brassica vegetables A review," LWT-Food Sci Technol, vol. 40, pp. 111,2007

[32] T.L. Rains, S. Agarwal, and K.C. Mak, "Antiobesity effects of green tea catechins: a mechanistic review," J Nutr Biochem, vol. 22, pp. 1-7, 2011.

[33] K. Maeda, and M. Fukuda, "Arbutin: mechanism of its depigmenting action in human melanocyte culture," J Pharmacol Exp Ther, vol. 276 , pp. 765-9, 1996.

[34] H. Fujiwara, Y. Tanaka, Y. Fukui, T. Ashikari, M.Yamaguchi, and T. Kusumi, "Purification and characterization of anthocyanin 3-aromatic acyltransferase from Perilla frutescens," Plant Sc, vol. 137, pp. 87-94, 1998.

[35] T. Patrice, "Depigmenting agent in compositions for treating skin cancer," French Patent 2759289, August 14, 17 p. 1998

[36] S. Kanai, and H. Okano, "Mechanism of the protective effects of sumac gall extract and gallic acid on CCl4-induced acute liver injury in rats," Am J Chin Med, vol. 26, pp. 333-341, 1998.

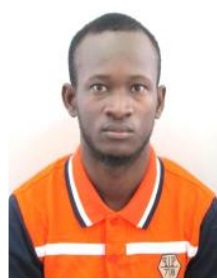

B. A. Kouakou was born on 28-02-1993 in Côte d'Ivoire. Boris Abel Kouakou is a Ph.D. student at Biosciences Faculty of University Félix HouphouëtBoigny. He has a Master of Biotechnology-BiosafetyBioresources at the same University precisely in the Biotechnology, Agriculture and Biological Resources Development Laboratory.

He is in the 3rd year of his thesis and works in the team of Prof. Mégnanou Rose-Monde. His research work focused on the valorization of shea butter are centered on the valorization of by-products of local agroresources. He has participated in Scientific Days, especially at the first scientific days organized at the University of Daloa on the valorization of natural substances of interest.

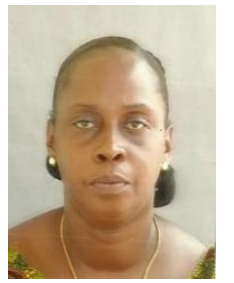

G. G. Doué was born on May 23, 1970, in Abidjan (Côte d'Ivoire). Mrs. Doué Ginette Gladys is assistant professor of CAMES universities and teacher researcher at Félix Houphouet-Boigny University Côte d'Ivoire since 2015. She has got Ph.D. in Biotechnology with a specialization in Biochemistry and Food Science, obtained with honours since 2014.

She has to her credit some twenty publications in peerreviewed and indexed journals and several communications on various biological materials (cassava, cocoa, shea, plant leaves, etc.), and has also supervised some ten master's theses. She advocates for the valorization of local plant resources in order to promote the food security and health of the population.

Dr. Doué is assistant manager of the UPR of Biotechnology in the Biotechnology, Agriculture, and valorization of Biological Resources laboratory. She is also a member of the Nutrition and Dietetics team.

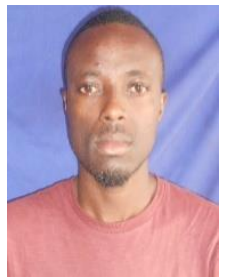

S. E. A. Djoman was born on 14-06-1991 in Abidjan (Côte d'Ivoire), Silas Elisée Ahouman DJOMAN is a Ph.D. student at the Faculty of Biosciences of the University Félix Houphouët Boigny. He holds a Master's degree in Biotechnology-BiosafetyBioresources at the same University in 2018.

$\mathrm{He}$ is in the second year of his thesis and works in the team of Prof. Mégnanou Rose-Monde. His research work focused on the valorization of shea butter are centered on the valorization of by-products of local agroresources. He has participated in Scientific Days, especially at the first scientific days organized at the University of Daloa on the valorization of natural substances of interest $\mathrm{He}$ also participated in many seminars organized in the biotechnology lab as part of his doctoral training. Details of the presenting author.

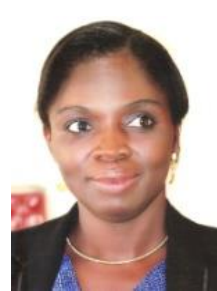

R.-M. MEGNANOU was born in 1971. Mrs. RoseMonde Megnanou is a Biochemist, Senior Lecturer at the University Félix Houphouët-Boigny, where she obtained with honor the doctorate in Biochemistry/Food Science, thirteen (13) years ago. She has about forty scientific publications and several communications at both national and international levels.

Her research work focuses on various biological materials (shea butter, cassava, vegetable leaves, sweet potato yellowish, etc.), but her main focus is on shea butter and its derivatives. She has supported her Ph.D., on "Optimization of traditional processes of shea" and now, she supervises two Ph.D., also on Vitellaria paradoxa and its by-products since 2018. In addition, she has also supervised about Twenty-five Master's degree under different themes.

Prof. Mégnanou is head of the NuTriFa (Nutrition and Food Formulation) team within the UPR Biotechnologies and has served as advisor to the laboratory director of Biotechnoligies. 